\title{
Chapter 9 \\ Conflicting Relations, Abuse and Discrimination Experienced by Older Adults
}

\author{
Charles Waldegrave, Marja Aartsen, Ariela Lowenstein, Marjaana Seppänen, \\ Mia Niemi, Maria Gabriella Melchiorre, and Giovanni Lamura
}

\subsection{Introduction}

Social relationships are generally considered a major resource for older people's health and well-being. They provide social connection and social meaning, and can provide instrumental and emotional support in times of ill health and crises in later life. However, not all relations function equally well. Conflicting relations, abuse, and discrimination also exist, and these are associated with social isolation, limited support, and increased discomfort as they involve the denial of resources, rights, goods and services, and limit the ability to participate in normal relationships and civic society (Dong 2015; Rook 2015; Aartsen et al. 2018; Burholt et al. 2019; Jackson et al. 2019). Hence, conflicting relations, elder abuse, and discrimination are related to many aspects of social exclusion.

These three dimensions of negative social relations have not been brought together in a single study previously. They have been drawn together in this chapter because they each focus on fundamentally demeaning social interactions that by definition, reduce social inclusion and quality of life (Darbonne et al. 2013; Dong

C. Waldegrave $(\bowtie)$

Family Centre Social Policy Research Unit, Lower Hutt, Wellington, New Zealand

e-mail: waldegrave.c@fc.org.nz

M. Aartsen

NOVA-Norwegian Social Research, Oslo Metropolitan University, Oslo, Norway
A. Lowenstein
Graduate Department of Aging Studies, Haifa University, Haifa, Israel
M. Seppänen · M. Niemi
Social Work, Faculty of Social Sciences, Helsinki Inequality Initiative (INEQ),
University of Helsinki, Helsinki, Finland

M. G. Melchiorre · G. Lamura

Centre for Socio-Economic Research on Ageing, INRCA-IRCCS,

National Institute of Health and Science on Ageing, Ancona, Italy 
2015; Jackson et al. 2019). Older people can find themselves in socially dysfunctional environments where the actions of others directly damage them. Elder abuse and discrimination, for example, have been shown to damage mental health and social relations. Known risk factors such as gender and socio-economic status [see previous chapters this section, and Barlin et al. this volume] can overlap with these (Dong 2015; Yunus et al. 2017). There is less research on conflictual relationships (Rook 2009), but that which does exist demonstrates harm to health and well-being.

Further, an in-depth consideration of cross-national evidence on these three dimensions is rare, with little analysis of how patterns relating to these phenomena, and their impacts, may differ across jurisdictions The cross-national evidence that does exist is largely confined to one of the dimensions, like abuse (Dong 2015; Yon et al. 2017) or discrimination (Kydd and Fleming 2015). This chapter brings together insights from a set of diverse research studies in five countries: Norway (Aartsen and Veenstra 2018), Finland (Seppänen and Niemi 2018), New Zealand (Waldegrave 2018), Israel (Lowenstein et al. 2009) and Italy (Melchiorre et al. 2012a) to show the importance of understanding these dysfunctional elements of relations in the conceptualisation of social exclusion in later life. The aim of this chapter is therefore to explore the complex nature of the conflicted, abusive and discriminative relations of older people and their differential exclusionary impacts across countries. We will consider each dimension in turn, commencing with conflicting relations, followed by elder abuse and then discrimination. In each section we will first review the international literature on these dimensions, and then draw on empirical evidence from the chosen studies to illustrate the impacts of such phenomena on the exclusionary experiences of older people. Finally, we present a discussion of our analysis and draw some conclusions.

\subsection{Conflicting Relations}

While the beneficial effects of being socially connected for health and well-being are widely acknowledged, social relations that are characterised by conflict may be equally disruptive to health and well-being. Conflicts in relations can refer to unpleasant social encounters that are characterised by criticism, rejection, competition, the violation of privacy, and the lack of reciprocity (Krause and Jay 1991). Family conflicts are particularly relevant as relationships with family members are difficult to terminate for older adults because of their increased dependency on family members and increased risk of declining health (Rook 2015).

However, research on the consequences of conflictual relations is limited (Rook 2009). The few studies that exist have observed that conflicts with other people are harmful for the health and well-being of the individual (Rook 2009; Darbonne et al. 2013). In addition, previous research suggests that there may be gender differences in the association between relationship conflicts and their outcomes, probably stemming from the different roles men and women fulfil within a couple (Iveniuk et al. 2014; see also Barlin et al. this volume). 
This current section aims to contribute to this knowledge gap by describing the prevalence, the duration or stability of the conflicts and the health outcomes of relations that are characterised by conflicts. It takes into account the potential moderating effect of age and gender and examines whether physical and mental health enhance the likelihood of partner conflict. The data are derived from the Norwegian Life Course Ageing and Generation Study (NorLAG) (Slagsvold et al. 2012). NorLAG has three waves of data collection; 2002/3, 2007/8, and 2017. Data on partner conflict were collected in the first two waves. In this study, a particular relation (for example with the partner) is seen as conflictual, if the individual selfevaluates and perceives a relation as being conflictual.

\subsubsection{Quantifying the Impacts of Conflicting Relations Between Partners: A Norwegian Study}

In wave 1,1251 people with a partner were asked whether they agree with the statement, "I often have conflicts with my partner". Slightly more than $10 \%(\mathrm{n}=129)$ of women and $7 \%(n=88)$ of men answered that they slightly agreed, agreed, or fully agreed. The difference in prevalence between men and women is significant (Chi $2=4.14, \mathrm{df}=1, \mathrm{p}=0.04$ ). The same question was repeated 5 years later, but with ten response categories. Recoding the responses into a five-category variable resulted in a higher prevalence of partner conflict, with $16.1 \%$ of men and $18.1 \%$ of women saying they often had conflicts with their partner. Gender differences were no longer statistically significant (Chi $2=1.54$, $\mathrm{df}=1, \mathrm{p}=0.22$ ).

The results of a logistic regression in which partner conflict at wave 2 (T2) ( $1=$ yes $/ 0=$ no) was regressed on partner conflict at wave 1 (T1), physical and mental health problems at T1, age, and gender are set out in Table 9.1. The HosmerLemeshow test (Chi2 $=12,35, \mathrm{df}=8, \mathrm{p}=0,14$ ) indicate a good model fit (Hosmer et al. 1980), and approximately $11 \%$ of the variation in conflicts with the partner at $\mathrm{T} 2$ is explained (Nagelkerke $\mathrm{R}^{2}=10.8$ ).

Table 9.1 Logistic regression of partner conflict in 2007 on partner conflict, gender, age, and physical and mental health in 2002

\begin{tabular}{l|r|l|r|l|l}
\hline & \multicolumn{1}{|l|}{ B } & S.E. & Wald & Sig. & $\operatorname{Exp(B)}$ \\
\hline Constant & 0.21 & 2.17 & 0.01 & 0.92 & 1.23 \\
\hline Partner conflict T1 & $\mathbf{2 . 2 1}$ & $\mathbf{0 . 6 9}$ & $\mathbf{1 0 . 2 7}$ & $\mathbf{0 . 0 0}$ & $\mathbf{9 . 1 3}$ \\
\hline Gender (men = 0, women = 1) & -0.53 & 1.25 & 0.18 & 0.68 & 0.59 \\
\hline Age & 0.00 & 0.01 & 0.00 & 0.99 & 1.00 \\
\hline Physical health T1 & $\mathbf{- 0 . 0 5}$ & $\mathbf{0 . 0 3}$ & $\mathbf{4 . 5 8}$ & $\mathbf{0 . 0 3}$ & $\mathbf{1 . 0 6}$ \\
\hline Mental health T1 & $\mathbf{- 0 . 0 9}$ & $\mathbf{0 . 0 3}$ & $\mathbf{8 . 3 4}$ & $\mathbf{0 . 0 0}$ & $\mathbf{0 . 9 2}$ \\
\hline Gender*Conflicts at T1 & -0.20 & 0.44 & 0.20 & 0.66 & 0.82 \\
\hline Gender*Physical health T1 & $\mathbf{- 0 . 0 3}$ & $\mathbf{0 . 0 2}$ & $\mathbf{5 . 1 7}$ & $\mathbf{0 . 0 2}$ & $\mathbf{0 . 9 7}$ \\
\hline Gender*Mental health T1 & $\mathbf{0 . 0 4}$ & $\mathbf{0 . 0 2}$ & $\mathbf{4 . 6 1}$ & $\mathbf{0 . 0 3}$ & $\mathbf{1 . 0 4}$ \\
\hline
\end{tabular}

Physical and mental health were measured using SF12 (Ware at al. 1996), with higher scores indicating better mental and physical health 
Partner conflict at T2 was best explained by partner conflict 5 years earlier. Gender and age did not predict partner conflict. Physical and mental health, as measured by the Short Form Health Survey 12 (SF12) (Ware et al. 1996) affected the odds of partner conflict 5 years later. Better physical and mental health was associated with a lower likelihood of partner conflict five years later. The effect of physical health on the odds of partner conflict was stronger for men than women, while the effect of mental health on the odds of partner conflict was stronger for women than men.

Finally, to explore the health consequences of conflictual relations with a partner, we conducted two linear regressions with mental and physical health at T2 as outcome variables. The results indicated that, after controlling for age and gender, partner conflict at T1 led to a significant decrease in mental health of two scale points on MCS12, an effect comparable to the gender difference in mental health. No significant effect of partner conflict on later physical health was observed.

A partner is often seen as the main source of support, and that is often justified. Sometimes, however, there is an inverse health effect, such as when a partner relationship is characterised by conflicts, as we described here. Even more devastating for health and well-being may be social relations that are characterised by violence, such as with abusive relations. That is the topic of the next section.

\subsection{Elder Abuse}

Elder abuse is an important human rights and public health issue (Yon et al. 2017). It is defined by the World Health Organisation (2018) as "a single, or repeated act, or lack of appropriate action, occurring within any relationship where there is an expectation of trust which causes harm or distress to an older person". It encompasses financial, physical, psychological and sexual exploitation, as well as intentional or unintentional neglect. Victims may suffer more than one type of abuse (Santos et al. 2019).

The lack of consensus in defining and measuring elder abuse has resulted in wide variations in reported prevalence rates. Cooper et al. (2008) reviewed 49 studies that examined prevalence in different countries. Reports ranged from $3.2 \%$ to $27.5 \%$, reflecting differences in methodology, definitions, and cultures. Yon et al. (2017) used meta-analysis to synthesise the prevalence estimate for elder abuse and its subtypes. Fifty-two studies from 28 countries qualified for the analysis. They concluded that the pooled prevalence rate for overall elder abuse from 44 studies was $15.7 \%$. In the subcategories, the pooled prevalence rate for psychological abuse was $11.6 \%$ from 44 studies, $6.8 \%$ for financial abuse (52 studies), $4.2 \%$ for neglect (30 studies), $2.6 \%$ for physical abuse (46 studies), and $0.9 \%$ for sexual abuse (15 studies).

The effects of elder abuse are complex and multidimensional. Studies identify a wide range of negative health outcomes (Fisher and Regan 2006), increased morbidity and mortality (Dong et al. 2013; Schofield et al. 2013) and psychological distress (Yunus et al. 2017). Systematic literature reviews show that elder abuse is associated with different aspects of exclusion from social relations such as social 
isolation (Murphy et al. 2013; Dong 2015), loneliness (Waldegrave 2015; Wong and Waite 2017), low social support (Dong et al. 2013), negative social well-being (Dong 2015), and interfamilial conflicts (Yan et al. 2002). Furthermore, it is associated with conditions that negatively impact on social relations such as poor mental health, psychological distress, anxiety, and suicidal thoughts (Lachs and Pillemer 2015; Yunus et al. 2017).

Three country studies make up the rest of this section on elder abuse. The studies in Israel and Italy show prevalence rates, types of abuse and important statistical associations as measured at a country level. The third study, from Finland, is of a qualitative design and explores social workers' records of elder abuse cases.

\subsubsection{Quantifying the Impacts of Elder Abuse: An Israeli Study}

The consensus in Israeli society had been that it was free from elder abuse. However, the number of older people who were referred to social work units has increased gradually. Thus, it was decided that a broad data base was needed: ESHEL (Association for Development of Social Services for Elders) and the Social Insurance Institute decided to conduct a large study on the topic. It was the first National Survey on Elder Abuse and Neglect in Israel and it challenged earlier perceptions (Lowenstein et al. 2009).

A random sample of 1045 adults aged 65+ participated, and findings showed that $18.4 \%$ experienced at least one type of abuse during the year preceding interview. Verbal abuse was the most prevalent (11.5\%), followed by financial exploitation $(6.6 \%)$ and physical and sexual abuse (2\%). Neglect by a significant other, with older people unable to meet the primary activities for daily living, was common and more than a quarter $(26 \%)$ experienced neglect in meeting both primary Activities of Daily Living (ADL) (basic self-care tasks like walking, eating, bathing and such) and secondary Instrumental Activities of Daily Living (IADL) (more complex tasks that require thinking and organisational skills like managing finances, shopping and meal preparation). Neglect of primary needs only was close to $18 \%$. A small proportion $(2.7 \%)$ suffered from limitation of freedom.

Regression analyses confirmed the earlier cited findings concerning health and different aspects of exclusion from social relations. Failing health was significantly associated with neglect and to a lesser extent with physical, sexual and verbal abuse, as set out in Table 9.2. Feelings of loneliness were strongly associated with verbal abuse and neglect, and to a lesser extent with limitation of freedom. Feelings of neglect were very strongly associated with neglect as would be expected, but also with financial exploitation.

The survey resulted in dynamic change regarding elder abuse and neglect, in research, policy, legislation, and social and health interventions. The Ministries of Health and Social Welfare for example, constructed a multidimensional, multisystemic approach to policy on elder abuse that increased public awareness and developed special social and health services, including building a specialised-care system (Lowenstein and Doron 2013). 
Table 9.2 Linear regressions for predicting abuse and/or neglect

\begin{tabular}{l|l|l|l|l|l}
\hline & $\begin{array}{l}\text { Physical \& } \\
\text { sexual abuse }\end{array}$ & Verbal abuse & $\begin{array}{l}\text { Limitation of } \\
\text { freedom }\end{array}$ & $\begin{array}{l}\text { Financial } \\
\text { exploitation }\end{array}$ & Neglect \\
\hline $\begin{array}{l}\text { Elders' } \\
\text { attributes }\end{array}$ & $\begin{array}{l}\text { Probability } \\
\text { ratio }\end{array}$ & $\begin{array}{l}\text { Probability } \\
\text { ratio }\end{array}$ & $\begin{array}{l}\text { Probability } \\
\text { ratio }\end{array}$ & $\begin{array}{l}\text { Probability } \\
\text { ratio }\end{array}$ & $\begin{array}{l}\text { Probability } \\
\text { ratio }\end{array}$ \\
\hline $\begin{array}{l}\text { Gender } \\
\text { (female) }\end{array}$ & NS & NS & NS & $\mathbf{0 . 3 6}^{\mathbf{t}}$ & NS \\
\hline $\begin{array}{l}\text { Nationality } \\
\text { (Jewish) }\end{array}$ & $\mathbf{0 . 1 6}^{\mathbf{t}}$ & NS & NS & NS & NS \\
\hline $\begin{array}{l}\text { Level of } \\
\text { income }\end{array}$ & NS & NS & $\mathbf{2 . 0 5}^{\mathbf{t}}$ & NS & NS \\
\hline Education & NS & $\mathbf{0 . 6 9}$ & NS & NS & NS \\
\hline Failing health & $\mathbf{1 . 7 9}$ & $\mathbf{1 . 2 5}$ & NS & NS & $* 1.38$ \\
\hline $\begin{array}{l}\text { Feelings of } \\
\text { neglect }\end{array}$ & NS & NS & NS & $\mathbf{1 . 4 0 *}$ & $\mathbf{2 . 5} * * *$ \\
\hline $\begin{array}{l}\text { Feelings of } \\
\text { loneliness }\end{array}$ & NS & $\mathbf{1 . 3 8 ^ { * * * * }}$ & $\mathbf{1 . 5 7 ^ { * }}$ & NS & $\mathbf{1 . 4} * * *$ \\
\hline
\end{tabular}

$\mathrm{t}<0.1 ;{ }^{*} \mathrm{p}<0.05 ;{ }^{*} \mathrm{p}<0.01 ; * * * \mathrm{p}<0.001 ; N S$ not significant

\subsubsection{Quantifying the Impacts of Elder Abuse: An Italian Study}

Similar results concerning health and different aspects of exclusion from social relations were found in Italy. Like the Israeli study, low socio-economic conditions including low income and low educational attainment were found to be significantly associated with elder abuse, albeit less strongly than in Israel.

The Italian component of the ABUEL (Abuse of the Elderly in the European region) cross-sectional survey found an overall prevalence rate for abuse of $13 \%$. Psychological and financial abuse were the most common, reaching $11 \%$ and $3 \%$ of cases, respectively. Lower percentages were found for neglect (1\%) and physical and sexual violence (1.5\%) (Melchiorre et al. 2012a).

The perpetrators of psychological abuse were mainly relatives (spouses/partners or children) and friends of the family, often acting as carers of older persons with dementia and/or situations with high levels of carer-care-recipient co-dependency (Fondazione Caritas Ambrosiana 2011). However, a significant proportion of financial abuse was perpetrated by non-relatives (Ligabue 2010; Melchiorre et al. 2012b).

The findings showed social isolation and lack of social support to be two dimensions of exclusion from social relations that were significantly linked with elder abuse, confirming earlier studies cited above (Murphy et al. 2013; Dong 2015) and the Israeli research. Poor health (including older people experiencing anxiety, depression, and physical complaints) was also identified as a key risk factor confirming previous research. Low socio-economic status (including low levels of income and/or education, especially for divorced and separated individuals) and limited autonomy were further crucial risk factors that were identified (Melchiorre et al. 2014; Badenes-Ribeira et al. 2019). 


\subsubsection{Elder Abuse Qualitatively Analysed: A Finnish Study}

The prevalence and complexity of elder abuse, as indicated in the Israeli and Italian studies, points to the need for gerontological social and health care professionals to have an understanding of the phenomenon, skills in its prevention and effective responses to its occurrence. A practice research approach implemented in a gerontological social work unit in Finland studied how social workers understand and describe elder abuse in family relations (Seppänen and Niemi 2018). The research employed a social reporting method developed at the city of Helsinki, based on Clinical Data Mining (Epstein 2010), that generates knowledge from direct social work practice. Clinical Data Mining utilises available agency data in its aims to identify service users' needs, connecting them to the macro-level context. The social reporting data were collected by social workers from social work service users' case records $(n=57)$ of elder abuse in 2017.

Content analysis identified numerous forms of abuse, such as physical, psychological (including violation of privacy, harassment, and disregard for selfdetermination), sexual and economic abuse, neglect, and the withholding of treatment, nutrition, or medication. Typically, client cases included many different forms of abuse.

Material and psychosocial interdependencies between family members, intergenerational marginalisation, and structural disadvantages increased the difficulty of disengaging from abusive relationships. Barriers to intervention were also identified, including the systemic failure to provide support and services for families with members in later life, particularly for the perpetrator relative. Analysis revealed that the abuse within families is often intertwined with structural factors and other individual and collective problems that affect families across the generations. Particular ethical considerations are required when assessing the client's need for safety alongside their need to maintain their family relationships.

Elder abuse is clearly a category of demeaning social interactions that reduces social inclusion and quality of life. Both it and conflictual relationships can be considered as dimensions of negative social relations. The third dimension we consider in this chapter is discrimination which follows in the next section.

\subsection{Discrimination}

Discrimination is generally defined as treating a person or particular group of people differently, especially to their disadvantage, because of their skin colour, sex, sexuality, age and other characteristics. Discrimination against older people has wide-ranging consequences: it harms older people's social inclusion, health, and well-being (Levy and Macdonald 2016; Jackson et al. 2019). Stereotyping older adults and ageist behaviour towards them leads to many ill-effects on older adults' 
lives, including lower levels of social integration, workforce barriers, abuse, and neglect (Lyons 2009; Vitman et al. 2013).

Alongside these negative impacts on well-being and social relations, age discrimination has wide-ranging impacts on older people's health. Perceived day-today age discrimination increased the odds of fair or poor self-rated health and a range of diseases compared with those who did not report discriminatory experiences, in a recent analysis of the English Longitudinal Study of Ageing (Jackson et al. 2019). A study of three waves of the US Health and Retirement Study suggested that perceived day-to-day discrimination may have broad health consequences through loneliness, especially for older adults with low education (Lee and Bierman 2018). Repeated exposure to chronic stressors associated with age stereotypes and discrimination is likely to increase the risk of chronic disease, mortality, and other adverse health outcomes (Allen 2015). A UK study found that older people with mental health problems were among the most socially excluded and stigmatised groups within mental health populations and the general population (Lievesley et al. 2009).

Six of these detrimental effects of discrimination were explored in two-waves of a New Zealand Study of older citizens. Associations between these dimensions and negative life impacts such as lower health, well-being, and social integration were analysed, and are summarised below.

\subsubsection{Quantifying the Impacts of Discrimination: A New Zealand Study}

The results from two waves of the New Zealand Longitudinal Study of Ageing (NZLSA) quantified the impacts of different forms of discrimination on the health, loneliness, depression, well-being, and social relationships of older people. A national random sample of 3,317 older New Zealand citizens aged 50-84 years was recruited, which reduced to 3,015 in wave two. Consistent statistical correlations were found between discrimination as measured by the Everyday Discrimination Scale (Williams et al. 1997; Williams 2012) and lower levels of both health and well-being, and higher levels of depression and loneliness (Waldegrave 2018).

In wave one (2010) almost $60 \%$ of respondents said they experienced some form of discrimination. This reduced to $53 \%$ in wave two (2012). Age discrimination $(15 \%)$ was the most frequently experienced form of discrimination. Employment, and intra-family ( $3 \%$ each), and gender and race ( $2 \%$ each) were the next most frequently cited forms of discrimination. On the 6-point scale used across each dimension of discrimination, the two most common expressions were "being treated with less courtesy and respect than other people" and "people acting as if they think you are not smart". Respectively $17 \%$ and $12 \%$ of respondents had experienced these at least a few times a year. 
The study analysed both static cross-sectional results from each wave and dynamic results over the two waves. Six social and health scales that measure known indicators of social exclusion cited in the literature above, were chosen to explore associations with discrimination in wave 2. Significant negative relationships were found between discrimination and each of the well-being and health scales, demonstrating that higher levels of discrimination are closely associated with lower health and well-being scores. As expected, loneliness and depression demonstrated significant positive relationships with discrimination. The cross-sectional results for wave two (2012) are shown in Table 9.3. In this table the discrimination scale measured in wave two (2012) is the independent variable used to predict each of the six social and health scales in wave two (2012).

The two waves of NZLSA data were then used to develop a dynamic measure to predict the well-being and health outcomes associated with discrimination. Instead of simply using the discrimination scale measured in wave two (2012) to predict well-being and health outcomes, the measure of discrimination in wave one (2010) is used as the dependent variable to predict the outcomes in wave two (2012). A linear regression model was applied for each dimension of well-being and health outcomes rather than using the six in one model, as some dimensions were correlated with each other.

In this dynamic analysis, we further control for the baseline outcome by including the measure of each dimension in wave one (2010) as one of the independent variables to predict the outcome in wave two (2012). This enabled the researchers to measure the impact of discrimination on social and health outcomes over time. Age, gender, education levels, and ethnicity were also controlled for. The results are set out in Table 9.4.

The P-value results show a statistically significant relationship between discrimination and each of the social exclusion indicators over the 2 years. Respondents with higher discrimination scores in wave one had decreased well-being and health scores, and higher loneliness and depression scores in wave two, demonstrating an increasing negative effect over time. The $\beta$ scores indicate that the impact is moderate, but consistent across the range of indicator variables.

Table 9.3 Linear regressions for predicting health and social variables in wave two (2012) using discrimination measured in wave two (2012)

\begin{tabular}{l|r|l}
\hline Dependent variable & \multicolumn{1}{l}{$\beta$} & P-value \\
\hline Well-being (WHOQoL-8) & -0.296 & $<0.01$ \\
\hline Well-being (CASP-12) & -0.315 & $<0.01$ \\
\hline SF 12 Physical Health & -0.114 & $<0.01$ \\
\hline SF 12 Mental Health & -0.294 & $<0.01$ \\
\hline Loneliness (de Jong Gierveld) & 0.332 & $<0.001$ \\
\hline Depression (CES-D) & 0.318 & $<0.001$ \\
\hline
\end{tabular}

Source: Waldegrave and Nguyen FCSPRU (2018) 
Table 9.4 Linear regression for predicting health and social variables in wave two (2012) using discrimination measured in wave one (2010)

\begin{tabular}{l|r|r|l}
\hline Dependent variable & \multicolumn{1}{|l|}{$\beta$} & P-value & $\mathrm{N}$ \\
\hline Well-being (WHOQoL - 8) in 2012 & -0.075 & 0.001 & 2660 \\
\hline Well-being (CASP - 12) in 2012 & -0.099 & $<0.001$ & 2616 \\
\hline SF 12 Physical Health in 2012 & -0.166 & 0.001 & 2296 \\
\hline SF 12 Mental Health in 2012 & -0.200 & $<0.001$ & 2296 \\
\hline Loneliness (de Jong Gierveld) in 2012 & 0.052 & 0.001 & 2492 \\
\hline Depression (CES-D) in 2012 & 0.083 & 0.001 & 2594 \\
\hline
\end{tabular}

Source: Waldegrave and Nguyen FCSPRU (2018)

\subsection{Conclusion}

This chapter brought together three dimensions of negative social relations as they impinge on and are experienced by older people, which have not been addressed together in previous studies. The aim was to explore, through the literature and original research conducted by the authors, how socially dysfunctional experiences affect social relations, and in turn impact on exclusion from social relations. Each dimension: conflictual relationships, abuse and discrimination, is characterised by demeaning social interactions that are important to address when considering social exclusion in ageing societies.

The studies cited across the dimensions, consistently demonstrated negative health, well-being and social disconnection impacts. Those on conflictual relationships showed that such relationships are harmful to health and well-being (Rook 2009; Darbonne et al. 2013). The studies on elder abuse came to similar conclusions with respect to the devastating effects of abusive relationships on health and quality of life (Lowenstein et al. 2009; Melchiorre et al. 2014). Other studies showed the strong associations of abuse with social isolation (Dong 2015), loneliness (Wong and Waite 2017) and low social support (Dong et al. 2013). The research on discrimination against older people showed the significantly negative impacts it has on older adult experiences of social inclusion, health and well-being (Levy and Macdonald 2016; Lee and Bierman 2018; Jackson et al. 2019). Higher levels of discrimination were closely associated with lower health and well-being scores, and higher loneliness and depression results (Waldegrave 2018).

Abuse and discrimination, by definition, refer to actions designed to hurt and exclude, while partnership conflict where an individual self-evaluates and perceives a relation as being conflictual, refers to the loss of harmony or partnership in the relationship. Each lead to demeaning interactions that damage social relations and disrupt social connections. These are dysfunctional processes, particularly when they happen to older people, and as the studies in this chapter show, they diminish feelings of self-worth, reduce well-being and sever relationships.

All three dimensions are usually studied within their own boundaries and have not previously been linked as a single research focus. They have been brought together in this chapter to demonstrate the similar way each dimension reduces the 
quality of life and social inclusion of older people. They function as exclusionary mechanisms within the social relations domain and have an important place in a conceptual framework of old-age social exclusion. This lens on the similarities and interrelationships of the three dimensions has enabled a broader understanding of exclusionary mechanisms.

This chapter addresses a key policy gap in more positive ageing frameworks. Each of these dimensions is modifiable. Public education, responsible professional training, media foci and improved inter-generational linkages can contribute to reducing the acceptance of dysfunctional behaviour that disrupts social inclusion. A policy focus on the linkages and interrelationships between exclusionary mechanisms in the social relations domain can enable more comprehensive and effective policy formation than a focus on one dimension at a time. Furthermore, it provides a broader human rights platform for the development of high-quality social services and more comprehensive policy development.

Future research could usefully consider the interrelationship between these three dimensions in further developing our understanding of the mechanisms that lead to social exclusion. Studies that address the dynamic effects of these mechanisms with more waves over a longer period will provide further robust evidence. Qualitative research that will help us get behind the numbers and better understand the complex web of vulnerability, dependency and victimisation will enable more realistic and effective social inclusionary policy development and service provision.

\section{Editors' Postscript}

Please note, like other contributions to this book, this chapter was written before the COVID-19 pandemic of 2020. The book's introductory chapter (Chap. 1) and conclusion (Chap. 34) consider some of the key ways in which the pandemic relates to issues concerning social exclusion and ageing.

\section{References}

Aartsen, M. J., \& Veenstra, M. (2018). The social pattern of conflicting and low-quality social relations. Paper presented at GSA 2018 Annual Meeting: The Purposes of Longer Lives, Massachusetts.

Aartsen, M., Valtorta, N., Dahlberg, L., Van Regenmortel S., Waldegrave, C., \& Corrigan, T. (2018). Exclusion from social relations in later life. ROSEnet Briefing Paper Series: No. 1. CA 15122 Reducing Old-Age Exclusion: Collaborations in Research and Policy.

Allen, J. O. (2015). Ageism as a risk factor for chronic disease. The Gerontologist, 56(4), 610-614.

Badenes-Ribera, L., Fabris, M. A., \& Longobardi, C. (2019). Elder mistreatment in an Italian population: Prevalence and correlates. The International Journal of Aging and Human Development. https://doi.org/10.1177/0091415019875454.

Burholt, V., Winter, B., Aartsen, M., et al. (2019). A critical review and development of a conceptual model of exclusion from social relations for older people. European Journal of Ageing (online first).https://doi.org/10.1007/s10433-019-00506-0. 
Cooper, C., Selwood, A., \& Lingston, G. (2008). The prevalence of elder abuse and neglect: A systematic review. Age and Aging, 37, 151-160.

Darbonne, A., Uchino, B. N., \& Ong, A. D. (2013). What mediates links between age and wellbeing? A test of social support and interpersonal conflict as potential interpersonal pathways. Journal of Happiness Studies, 14(3), 951-963.

Dong, X. (2015). Elder abuse: systematic review and implications for practice. Journal of the American Geriatrics Society, 63(6), 1214-1238.

Dong, X., Chen, R., Chang, E. S., \& Simon, M. (2013). Elder abuse and psychological well-being: A systematic review and implications for research and policy-A mini review. Gerontology, 59(2), 132-142.

Epstein, I. (2010). Clinical data-mining: Integrating practice and research. Oxford: Oxford University Press.

Fisher, B., \& Regan, S. (2006). The extent and frequency of abuse in the lives of older women and their relationship with health outcomes. Gerontologist, 46(2), 200-209.

Fondazione Caritas Ambrosiana. (2011). Ferite invisibili. Il mal-trattamento psicologico nella relazione tra caregiver e anziano (Invisible wounds. The psychological mistreatment in the relationship between caregiver and elder). Milano: Franco Angeli. (in Italian).

Hosmer, D. W., Hosmer, T., \& Lemeshow, S. (1980). A goodness-of-fit tests for the multiple logistic regression model. Communications in Statistics, 10, 1043-1069.

Iveniuk, J., Waite, L. J., Laumann, E., McClintock, M. K., \& Tiedt, A. D. (2014). Marital conflict in older couples: Positivity, personality, and health. Journal of Marriage and Family, 76(1), $130-144$.

Jackson, S. E., Hackett, R. A., \& Steptoe, A. (2019). Associations between age discrimination and health and wellbeing: cross-sectional and prospective analysis of the English Longitudinal Study of Ageing. The Lancet Public Health, 4(4), e200-e208.

Krause, N., \& Jay, G. (1991). Stress, social support and negative interaction in later life. Research on Aging, 13, 333-363.

Kydd, A., \& Fleming, A. (2015). Ageism and age discrimination in health care: Fact or fiction? A narrative review of the literature. Maturitas, 81(4), 432-443.

Lachs, M. S., \& Pillemer, K. A. (2015). Elder abuse. New England Journal of Medicine, 373(20), 1947-1956.

Lee, Y., \& Bierman, A. (2018). Loneliness as a mediator of perceived discrimination and depression: Examining education contingencies. International Journal of Aging \& Human Development, 89(2), 206-227.

Levy, S., \& Macdonald, J. (2016). Progress on understanding ageism. Journal of Social Issues, $72(1), 5-25$.

Lievesley, N., Hayes, R., Jones, K., Clark, A. (2009). Ageism and age discrimination in mental health care in the United Kingdom: A review from the literature.. Centre for Policy on Ageing.

Ligabue, L. (2010). Progetto DIADE: attività svolte ed elementi emersi dal progetto (DIADE Project: activities and outcome). Conference 'DIADE Violenza agita e subita nella relazione di cura: ricerca, analisi, proposte per prevenirla ed affrontarla', Reggio Emilia. http://www. informanziani.it/docs/LL.pdf. (in Italian). Accessed 22 Jan 2019.

Lowenstein, A., \& Doron, I. (2013). Israel. In A. Phelan (Ed.), International perspectives on elder abuse (pp. 97-121). London/New York: Routledge, Taylor and Francis Group.

Lowenstein, A., Eisikovits, Z., Band-Winterstein, T., \& Enosh, G. (2009). Is elder abuse and neglect a social phenomenon? Data from the first national prevalence survey in Israel. Journal of Elder Abuse and Neglect, 21(3), 253-277.

Lyons, I. (2009). Public perceptions of older people and ageing. Dublin: National Centre for the Protection of Older People.

Melchiorre, M. G., Di Rosa, M., Lamura, G., Quattrini, S., Chiatti, C., Greco, C., \& Soares, J. J. F. (2012a). Il maltrattamento delle persone anziane in Italia: alcuni risultati dallo Studio 
Abuel (The mistreatment of the elderly in Italy: some findings from the Abuel Study). Prospettive Sociali e Sanitarie, 3, 16-19. (in Italian).

Melchiorre, M. G., Chiatti, C., \& Lamura, G. (2012b). Tackling the phenomenon of elder abuse in Italy: A review of existing legislation and policies as learning resource. Educational Gerontology, 38(10), 699-712.

Melchiorre, M. G., Penhale, B., \& Lamura, G. (2014). Understanding elder abuse in Italy: Perception and prevalence, types and risk factors from a review of the literature. Educational Gerontology, 40(12), 909-931.

Murphy, K., Waa, S., Jaffer, H., Sauter, A., \& Chan, A. (2013). A literature review of findings in physical elder abuse. Canadian Association of Radiologists Journal, 64(1), 10-14.

Rook, K. S. (2009). Gaps in Social Support Resources in Later Life: An Adaptational Challenge in Need of Further Research. Journal of Social and Personal Relationships, 26(1), 103-112.

Rook, K. S. (2015). Social networks in later life: Weighing positive and negative effects on health and well-being. Current Directions in Psychological Science, 24(1), 45-51.

Santos, A. J., Nunes, B., Kislaya, I., et al. (2019). Elder abuse victimization patterns: Latent class analysis using perpetrators and abusive behaviours. BMC Geriatr, 19, 117.

Schofield, M. J., Powers, J. R., \& Loxton, D. (2013). Mortality and disability outcomes of selfreported elder abuse: a 12-year prospective investigation. Journal American Geriatric Society, 61, 679-685.

Seppänen, M. \& Niemi, M. (2018, 11 15). Exclusion from supportive social relations-elder abuse in family. Paper presented at GSA 2018 Annual Meeting: The Purposes of Longer Lives, Massachusetts.

Slagsvold, B., Veenstra, M., Daatland, S. O., Hagestad, G., Hansen, T., Herlofson, K., \& Solem, P. E. (2012). Life-course, ageing and generations in Norway: the NorLAG study. Norsk Epidemiologi, 22(2), 95-102.

Vitman, A., Iecovich, E., \& Alfasi, N. (2013). Ageism and social integration of older adults in their neighborhoods in Israel. The Gerontologist, 54(2), 177-189.

Waldegrave, C., (2015) Measuring elder abuse in New Zealand: Findings from the New Zealand longitudinal study of ageing (NZLSA). (Technical Paper, Office for Senior Citizens). Wellington: Ministry of Social Development, New Zealand.

Waldegrave, C., \& Nguyen, G. (2018). The impacts of discrimination and abuse on the health, well-being, and loneliness of older people. Paper presented at GSA 2018 Annual Meeting: The Purposes of Longer Lives, Massachusetts.

Ware, J. E., Jr., Kosinski, M., \& Keller, S. D. (1996). A 12-Item Short-Form Health Survey: Construction of scales and preliminary tests of reliability and validity. Medical Care, 220-233.

Williams, D. (2012). The everyday discrimination scale. In D. Williams (Ed.), Measuring discrimination resource. https://scholar.harvard.edu/files/davidrwilliams/files/measuring_discrimination_resource_feb_2012_0_0.pdf. Accessed 22 Apr 2020.

Williams, D. R., Yu, Y., Jackson, J. S., \& Anderson, N. B. (1997). Racial differences in physical and mental health: Socioeconomic status, stress, and discrimination. Journal of Health Psychology, 2(3), 335-351.

Wong, J. S., \& Waite, L. J. (2017). Elder mistreatment predicts later physical and psychological health: Results from a national longitudinal study. Journal of Elder Abuse \& Neglect, 29(1), 15-42.

World Health Organization. (2018). Elder abuse. Geneva: World Health Organization. https:// www.who.int/ageing/projects/elder_abuse/en/ Accessed 22 Apr 2020.

Yan, E., So-Kum, C., \& Yeung, T. D. (2002). No safe haven: A review on elder abuse in Chinese families. Trauma, Violence, \& Abuse, 3(3), 167-180.

Yon, Y., Mikton, C. R., Gassoumis, Z. D., \& Wilber, K. H. (2017). Elder abuse prevalence in community settings: A systematic review and meta-analysis. Lancet Global Health, 5, 147-156.

Yunus, R. M., Hairi, N. N., \& Choo, W. Y. (2017). Consequences of elder abuse and neglect: A systematic review of observational studies. Trauma, Violence, \& Abuse. Advance online publication. https://doi.org/10.1177/1524838017692798 
Open Access This chapter is licensed under the terms of the Creative Commons Attribution 4.0 International License (http://creativecommons.org/licenses/by/4.0/), which permits use, sharing, adaptation, distribution and reproduction in any medium or format, as long as you give appropriate credit to the original author(s) and the source, provide a link to the Creative Commons license and indicate if changes were made.

The images or other third party material in this chapter are included in the chapter's Creative Commons license, unless indicated otherwise in a credit line to the material. If material is not included in the chapter's Creative Commons license and your intended use is not permitted by statutory regulation or exceeds the permitted use, you will need to obtain permission directly from the copyright holder. 